\title{
The application of polypropylene mesh for testicular prosthesis in surgical castration for patients with prostate cancer
}

\author{
Yao-Hui Xia', Wei Huang ${ }^{2}$, Chun-Xiao Yu², Bo Kong², Rui Qin², Peng-Fei Wang ${ }^{2}$, Jie $\mathrm{An}^{2}$ and Yong-Qiang Xia ${ }^{1 *}$
}

\begin{abstract}
Background: To explore whether a polypropylene mesh is suitable for application as a new material for testicular prostheses.

Methods: The data of 65 patients with advanced prostate cancer who underwent surgical castration in hospital were collected and analyzed. Patients who preferred to undergo traditional orchidectomy $(n=16)$ were assigned to the control group, and patients who underwent subcapsular orchiectomy plus implantation of a polypropylene mesh testicular prosthesis $(n=49)$ were assigned to the experimental group. The presence of hematoma, infection, and other complications in patients in these two groups were investigated at 3 and 12 months following the surgery. The patients were also followed up using a self-designed testicular castration satisfaction questionnaire.

Results: A higher score indicated greater satisfaction. The mean score was $15.33 \pm 2.85$ in the experimental group and $4.63 \pm 1.45$ in the control group at 3 months after the surgery. The mean score was $14.92 \pm 1.74$ in the experimental group and $4.25 \pm 1.61$ in the control group at 12 months after the surgery. The difference between the two groups was statistically significant at the two time points $(P<0.01)$.

Conclusions: Compared with orchidectomy alone, patients were more satisfied with subcapsular orchiectomy plus the implantation of a polypropylene mesh testicular prosthesis for the treatment of advanced prostate cancer. Furthermore, the polypropylene mesh testicular prosthesis maintained its original character over the duration of the study, with a good long-term effect. Thus, implantation of a polypropylene mesh testicular prosthesis is indicated to be safe and effective, and polypropylene mesh is potentially useful as a new material for testicular prostheses.
\end{abstract}

Keywords: Prostate cancer, Surgical castration, Polypropylene mesh for testicular prosthesis, Testicular prosthesis

\section{Introduction}

Studies have revealed that the incidence of prostate cancer is becoming significantly higher in men $>60$ year old $[1,2]$. Among these patients, some patients lose the chance of radical surgery due to serious cardiovascular disease, pulmonary dysfunction, and other diseases [3]. Some patients refuse simple endocrine therapy due to heavy economic burden and are afraid of the inferiority complex when facing orchidectomy. Hence, this segment of patients often gives up the opportunity of treatment. To date, China could not produce qualified testicular

\footnotetext{
*Correspondence: xiayongqiangdoc@163.com

'Department of Urology, Women and Children's Hospital of Linyi City, NO.1

Qinghe South Road, Luozhuang District, Linyi 276000, China

Full list of author information is available at the end of the article
}

prostheses due to histocompatibility, while imported testicular prostheses are expensive. Furthermore, the problem of infection and other complications remains unresolved. Therefore, very few patients undergo testicular prosthesis implantation after surgical castration, which severely limits the number of patients who received this treatment $[4,5]$. Therefore, patients with advanced prostate cancer from January 2011, who require surgical castration in our hospital, underwent the pilot treatment of subalbugineous testicular evisceration plus the implantation of polypropylene mesh testicular prostheses using a self-designed testicular prosthesis. The histocompatibility of this prosthesis was observed, the satisfaction of these patients was followed-up using a self-designed testicular castration satisfaction questionnaire, and the scores of

(C) The Author(s). 2019 Open Access This article is distributed under the terms of the Creative Commons Attribution 4.0 International License (http://creativecommons.org/licenses/by/4.0/), which permits unrestricted use, distribution, and 
these patients were recorded and statistically analyzed. By comparing with traditional orchidectomy, the safety and effectiveness of the implantation of the polypropylene mesh testicular prosthesis were evaluated, and it was determined whether a polypropylene mesh could be used as a new material for testicular prosthesis. Patients who preferred to undergo traditional orchidectomy were assigned to the control group. The histocompatibility and the satisfaction following surgical castration of the two groups of patients were compared. Details are reported as follows.

\section{Methods}

\section{General data}

Data of 65 patients with advanced prostate cancer, who underwent surgical castration in our hospital from January 2011 to March 2016, were collected and analyzed. Based on their preferences for the treatment options, 49 patients underwent subalbugineous testicular evisceration plus implantation of polypropylene mesh testicular prosthesis and were assigned into the experimental group. The mean age of these patients was $76.1 \pm 4.5$ years old, and mean preoperative serum prostate-specific antigen (PSA) levels were $49.3 \pm 18.2 \mu \mathrm{g} / \mathrm{ml}$. Furthermore, among these patients, 7 patients were in stage T3 and 11 patients was in stage T4. Bone scan revealed bone metastases in 11 patients. In addition, in terms of Gleason scores, 9 patients had $\leq 6$ points, 13 patients had 7 points, and 27 patients had $\geq 8$ points. In the control group, 16 patients received bilateral orchidectomy. The mean age of these patients was $75.6 \pm 6.6$ years old, and the mean preoperative PSA was $53.9 \pm 20.4 \mu \mathrm{g} / \mathrm{ml}$. Furthermore, among these patients, 3 patients were in stage T3 and 5 patients were in stage T4. Bone scan revealed bone metastases in 2 patients. In terms of Gleason scores, 4 patients had $\leq 6$ points, 3 patients had score of 7 points, and 9 patients had $\geq 8$ points. Statistical analysis revealed that differences in age, preoperative PSA, tumor stage, and Gleason score between the experimental group and control group were not statistically significant (Table 1 ).

\section{Production and details of the polypropylene mesh testicular} prosthesis

The testicular prosthesis was made of a polypropylene mesh provided by China Holycon Medical Supplies Co. Ltd. (Nantong, Jiangsu; patent name: testicular prosthesis, patent no.: ZL 201320681687.0, patent owner: Yongqiang Xia). This prosthesis was used in clinical practice after the approval of the Ethics Committee of the Central Hospital of Zaozhuang Mining Group of Shandong Province. Families of the patients were informed that the polypropylene mesh testicular prosthesis is not a testicular prosthesis certified by the China Food and Drug Administration, but a scrotum filling material made of medical materials, and the purpose of the implantation is to maintain the male self-esteem. Written informed consent was obtained from all patients.

\section{Surgical methods}

\section{Surgical method for the experimental group}

Patients were laid in the supine position. General disinfection was performed, and surgical drapes were placed on the lower abdomen and scrotum. After the success of systemic or local anesthesia, palpation was performed to determine the size, shape, and texture of the testis and epididymis. The testis was adjusted to facilitate its free exterior edge to be the operative field, and the epididymis was placed in the deep part of the testis. The epididymis and testis were fixed by the left hand of the surgeon, while the assistant helped tighten the skin of the scrotum, in order to expose the incision of each layer. The skin and dartos coat were cut by the surgeon with a knife using his right hand. Next, the fascia spermatica externa, cremaster muscles, fascia spermatica interna, and tunica vaginalis of parietal layer were cut off layer by layer using an electrotome. Thus, the vaginal cavity was exposed, hydrocele and accessory calcium salt were removed, and iodophor disinfection was performed when necessary. Finally, the tunica vaginalis of the visceral layer and tunica albuginea were cut off. The polypropylene mesh testicular prostheses were previously produced with appropriate shapes. The contents of the

Table 1 Demographics and perioperative data of patients

\begin{tabular}{|c|c|c|c|}
\hline & & Control group $(n=16)$ & Experimental group $(n=65)$ \\
\hline Mean age (years) & & $75.6 \pm 6.6$ & $76.1 \pm 4.5$ \\
\hline PSA level ( $\mu \mathrm{g} / \mathrm{ml})$ & & $53.9 \pm 20.4$ & $49.3 \pm 18.2$ \\
\hline \multirow[t]{2}{*}{ Stages of cancer $(n)$} & Stage T3 & 7 & 3 \\
\hline & Stage T4 & 11 & 5 \\
\hline Bone metastases $(n)$ & & 11 & 2 \\
\hline \multirow[t]{3}{*}{ Gleason scores (n) } & $\leq 6$ points & 9 & 4 \\
\hline & 7 points & 13 & 3 \\
\hline & $\geq 8$ points & 27 & 9 \\
\hline
\end{tabular}


testis were removed with a scoring tooth or a surgical knife handle. When obvious active bleeding occurred on the inner surface of the tunica albuginea, only appropriate electrocautery was conducted, in order to protect the blood supply of the tunica albuginea. The pre-made polypropylene mesh testicular prosthesis was implanted, and the tunica albuginea was continuously sutured with absorbable 4-0 suture. The testicular prosthesis and epididymis were adjusted to a suitable position, and two to three radial incisions were made on the tunica vaginalis of the wall layer with an electric knife, where the testis was located in the center of the incisions. Next, adequate hemostasis was performed. Interrupted suture was performed on the fascia spermatica externa, cremasteric muscle, and fascia spermatica interna (with three stitches each). The skin of the scrotum and dartos coat was sutured for three stitches for each layer. No drainage was placed in the incisions, while incisions were not treated with pressurized bandage. The contralateral implantation was treated in the same way. The appearance of the testicular prosthesis is shown in Fig. 1a. The appearance after testicular evisceration is shown in Fig. 1b. The appearance of the testis after the tamponage of testicular prosthesis is shown in Fig. 2a. In addition, the appearance of the scrotum after testicular prosthesis implantation is shown in Fig. $2 \mathrm{~b}$.

\section{Operation method in the control group}

The surgical procedures applied were the same as that in traditional orchiectomy.

\section{Evaluation method}

The presence of hematoma, infection, and other complications in patients in these 2 groups were observed at 3 months and 12 months after the operation. The occurrence of prosthesis piercing the skin and autoimmune diseases were observed in the experimental group. A testicular castration satisfaction questionnaire was developed according to the concerned problems of patients and in reference to Kiyak's satisfaction questionnaire [6] (Table 2). The scores of the 2 groups of patients were investigated at the above 2 time points using this questionnaire. Part of the patients failed to complete the 2 reviews and the 2 questionnaires due to lost to follow-up. At 3 months after the operation, 49 copies of questionnaires were completed in the experimental group, while 16 copies were completed in the control group. At 12 months after the operation, 45 copies of questionnaire were completed in the experimental group, while 15 copies were completed in the control group.

\section{Scoring method}

Data in each item in the questionnaire were statistically processed. In the 5 columns of specific evaluation, the scores from left to right were 2 points, 1 point, 0 points, -1 point, and -2 points. Next, the average of the original scores was calculated and assigned as the satisfaction score. The higher the satisfaction score is, the higher the satisfaction degree of the patients on the operation is. The satisfaction scores between groups were compared using the Student $t$ test.

\section{Result}

At 3 months and 12 months after the operation, no scrotum hematoma, infection, and other complications occurred in the two groups. No prosthesis pierced the skin in the experimental group, and no autoimmune disease was found (Figs. 3 and 4 and Table 3).

The satisfaction score was significantly higher in the experimental group than in the control group, and the difference between these two groups was statistically significant $(P<0.01)$. At 3 months and 12 months after the operation, intra-group differences within both the experimental group and control group were not statistically significant $(P>0.05)$. No complications induced by prosthesis were found in
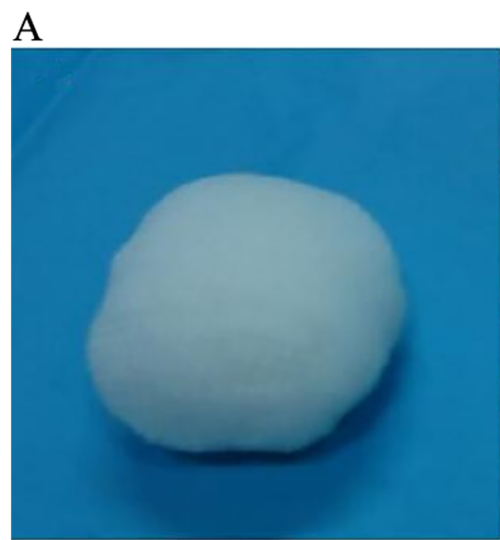

B

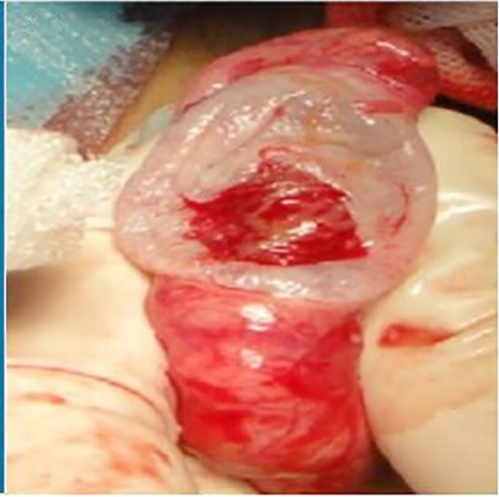

Fig. 1 Testicular prosthesis (a) and orchiectomy (b) 
A

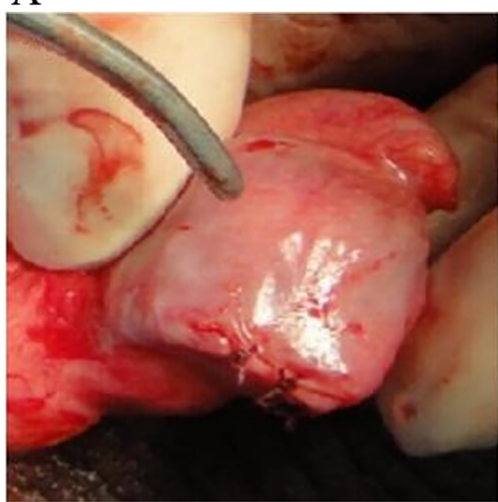

B

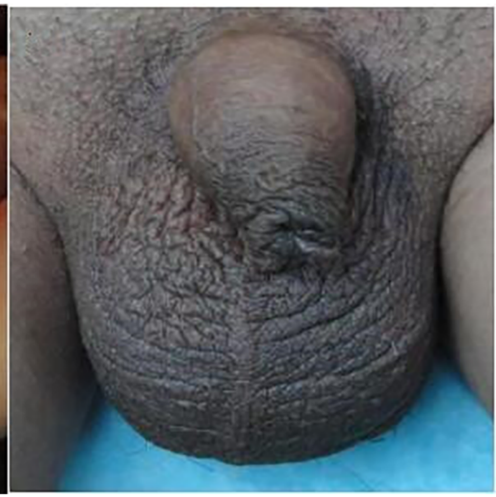

Fig. 2 Testicular prosthesis implantation (a) and scrotal appearance after implantation (b)

patients in the experimental group after being followed up for 1-5 years. However, statistical processing of satisfaction scores on this item was not conducted due to incomplete data.

\section{Discussion}

In the global scale, the incidence of prostate cancer ranks second in all malignant tumors in men. Its incidence continues to increase year by year in China [7]. Since most prostate cancers are androgen-dependent and surgical castration, namely removal of the testes, can decrease serum testosterone by $95 \%$, the lesions and symptoms of prostate cancer can be significantly alleviated. Androgen is secreted from interstitial cells in the testis. These types of cells are located in the testicular parenchyma. Therefore, subalbugineous testicular evisceration is a feasible way of surgical castration for patients with prostate cancer.

Orchidectomy has a close correlation to the quality of life of patients with prostate cancer. This is one of the important reasons for the decline in the quality of life of patients and has different degrees of influence on the physical function, role function, emotional function, cognitive function, and social function of patients [8-10]. This requires that more attention should be given to the adverse effects of orchidectomy on patients. Determining how to maximally reduce and avoid the influence of the quality of life of patients remains an urgent problem to be solved in clinical practice. Therefore, the implantation of a testicular prosthesis after castration would be a good remedy for prostate cancer patients, which is particularly important to reshape the appearance of men. Some studies found that the implantation of testicular prosthesis could significantly improve the self-image of patients undergoing orchidectom y[11]. Previously, testicular prostheses include $\mathrm{Co}-\mathrm{Cr}-\mathrm{Mo}$ alloy testicular prosthesis, synthetic resin testicular prosthesis, glass bead testicular prosthesis, dacron testicular prosthesis, polyethylene testicular prosthesis, silica gel testicular prosthesis [12], and tissue engineering cartilage testicular prosthesis [13]. However, the shortcomings of these prostheses include expensive price and susceptibility to postoperative complications such as pain, discomfort, scrotum

Table 2 The score distribution diagram of satisfaction of surgical castration

\begin{tabular}{|c|c|c|c|c|c|}
\hline \multirow[t]{2}{*}{ Observation item } & \multicolumn{5}{|c|}{ Specific evaluation of each patient in two groups } \\
\hline & 2 points & 1 point & 0 point & -1 point & -2 point \\
\hline 1. Appearance of scrotum & Quite satisfied & Satisfied & Common & Dissatisfied & Quite dissatisfied \\
\hline 2. Size of scrotum & Quite satisfied & Satisfied & Common & Dissatisfied & Quite dissatisfied \\
\hline 3. Rigidity of scrotum & Quite satisfied & Satisfied & Common & Dissatisfied & Quite dissatisfied \\
\hline 4. Special discomfort of scrotum & None & Not obvious & A little & Obvious & Quite obvious \\
\hline 5. Degree of self-respect & Quite satisfied & Satisfied & Common & Dissatisfied & Quite dissatisfied \\
\hline 6. Adverse reactions & None & Not serious & Common & Serious & Quite serious \\
\hline 7. Feeling of invasive manipulation & Quite satisfied & Satisfied & Common & Dissatisfied & Quite dissatisfied \\
\hline 8. Effectiveness evaluation of household & Quite satisfied & Satisfied & Common & Dissatisfied & Quite dissatisfied \\
\hline 9. Impact of other factors (financial condition) & Quite small & Small & Common & Big & Quite big \\
\hline 10. Would like to recommend to friends? & Quite willing & Willing & Common & Unwillingness & Quite unwillingness \\
\hline
\end{tabular}




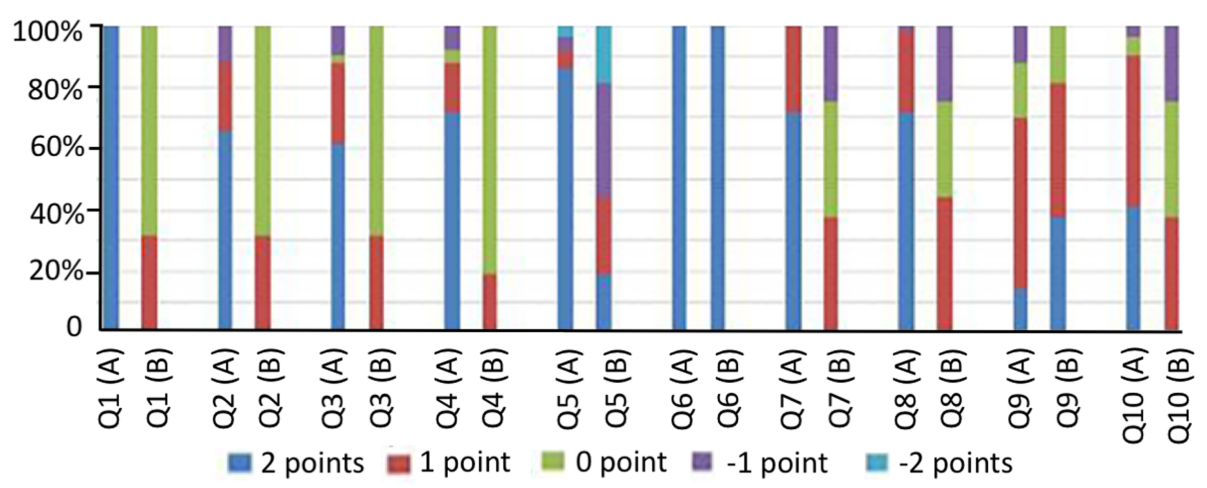

\section{A: Experimental group \\ B: control group}

Fig. 3 The score distribution diagram of satisfaction of testicular prosthesis 3 months after surgery. A: experimental group; B: control group; Q: question in the questionnaire

hematoma, incision infections, and contracture of fibrous capsule around the prosthesis after surgery [14], which limits the development of the implanted testicular prosthesis.

Studies have confirmed that connective tissue ingrew into the meshes and formed an integrated and stable fibrous capsule after the implantation of polypropylene meshes, which reveal that the polypropylene mesh had a good histocompatibility [15]. Medical products made of polypropylene mesh have been widely used in pelvic floor reconstruction, hernia repair, and other fields, which have obtained good clinical results [15-17].

Prior to this present study, there are no related reports on polypropylene mesh testicular prosthesis at home and abroad [18]. Since the quantification standard of the effect after orchidectomy and testicular prosthesis implantation could not be searched, and in order to evaluate the application value of the implantation of the polypropylene mesh testicular prosthesis for prostate cancer patients undergoing surgical castration, the investigator for this study developed an observation questionnaire of testicular surgery using the following three items: the sense of the testis size, the sense of testicular rigidity, and the special indisposition of the testis. Most patients in the control group had a score of zero, since they recognized the objective condition of the loss of testis before surgery. However, the problem on whether the "testis" was good or bad was not present in these patients. Moreover, two patients considered that there were no bad to lose testis; thus, a score of 1 point was given. In the survey item "the impact of economic factors and other factors," the scores were lower in the experimental group than in the control group. In the remaining survey items, the scores were higher in the experimental group than in the control group. This study found that when the polypropylene mesh testicular prosthesis was implanted into the albuginea in the testis, the testicular prosthesis and tissue exhibited an

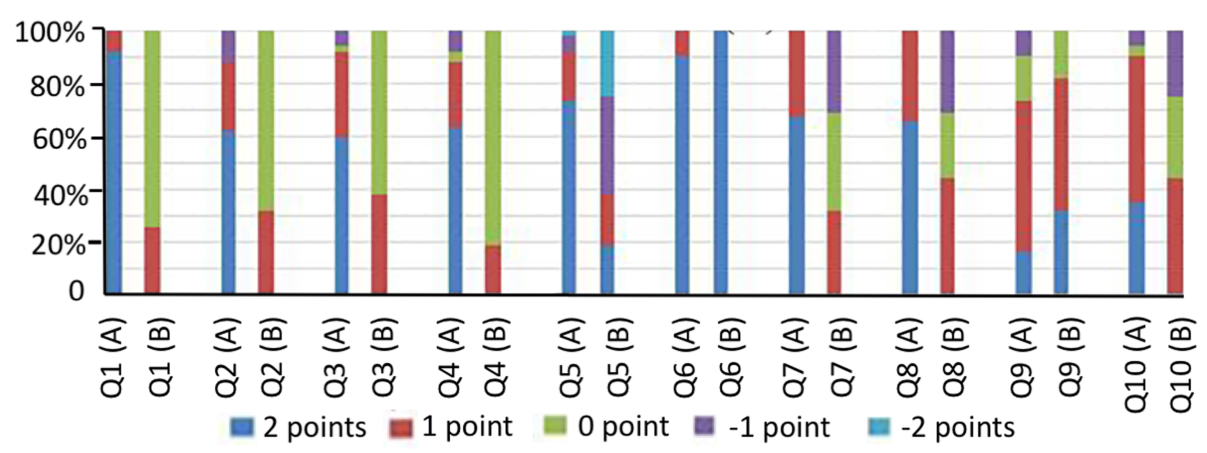

\section{A: Experimental group \\ $B$ : control group}

Fig. 4 The score distribution diagram of satisfaction of testicular prosthesis 12 months after surgery. A: experimental group; B: control group; Q: question in the questionnaire 
Table 3 The comparison of score distribution diagram for the satisfaction of surgical castration $(\bar{x} \pm S)$

\begin{tabular}{llll}
\hline Groups & Scores at 3 months after operation & Scores at 12 months after operation & $P$ value \\
\hline Experimental group & $15.33 \pm 2.85$ & $14.92 \pm 1.74$ & $>0.05$ \\
Control group & $4.63 \pm 1.45$ & $4.25 \pm 1.61$ & $>0.05$ \\
$P$ value & $<0.01$ & $<0.01$ & \\
\hline
\end{tabular}

embedded combination. This exhibited good histocompatibility, no prosthesis infection, other complications and adverse reactions occurred after surgery, and no local discomfort and other problems appeared. Compared with traditional orchidectomy, the risk of the operation did not increase. This was consistent with the results of the study conducted by Robinson $\mathrm{R}$ et al. [19]. Due to the presence of the testicular prosthesis, the appearance of the scrotum was normal after the operation; hence, the pride of patients was not hurt. Differences in the size and rigidity of the "testis" did not affect the psychological feeling of the patient. The postoperative evaluation of surgical results from patients and their family members were all high, and they were willing to recommend this surgical procedure to their friends. The scores of patients in the experiment group at 3 months and 12 months after surgery did not show a significant change. This suggests that the polypropylene mesh testicular prosthesis continued to maintain a relatively safe and effective character with time after implantation.

Retaining the normal scrotum appearance produced a positive comforting effect for the emotional function of the patient; hence, the overall quality of life of patients was improved. In addition, a study found that good emotional control could have a positive effect on the prognosis of cancer patients [20].

\section{Conclusions}

Therefore, the implantation of polypropylene mesh testicular prosthesis did not increase the risk of surgery and could significantly improve the overall living conditions of patients with advanced prostate cancer. The application of polypropylene mesh testicular prosthesis not only enriches the types of testicular prosthesis, but also promotes the development of testicular prosthesis implantation in patients with prostate cancer. Patients with economic difficulties did not need to bear the high cost of endocrine therapy, which had a greater application value. The author plans to carry out further follow-up studies, in order to promote this self-designed polypropylene mesh testicular prosthesis as a real medical product. Furthermore, the author also plans to gradually extend the application of the implantation of the polypropylene mesh testicular prosthesis to anorchia patients induced by other causes.

Abbreviations

PSA: Prostate-specific antigen

\section{Acknowledgements}

None.

Authors' contributions

YHX was involved in drafting the manuscript and revising it critically for important intellectual content. WH and CXY made substantial contributions to conception and design of the work. BK, RQ, PFW, and JA made substantial contributions to the acquisition, analysis, and interpretation of data for the work. YQX participated in the data interpretation and reviewed the manuscript. All authors gave the final approval of the version to be published.

Funding

Not applicable.

Availability of data and materials

All data generated or analyzed during this study are included in this published article [and its supplementary information files].

Ethics approval and consent to participate

This study was conducted in accordance with the declaration of Helsinki. This study was approved by the Ethics Committee of Central Hospital of Zao Zhuang Mineral Group. Written informed consent was obtained from all participants.

\section{Consent for publication}

We have obtained consent to publish from the participants (or legal parent or guardian) to report their individual patient data.

\section{Competing interests}

The authors declare that they have no competing interests.

\section{Author details}

${ }^{1}$ Department of Urology, Women and Children's Hospital of Linyi City, NO.1 Qinghe South Road, Luozhuang District, Linyi 276000, China. ²Department of Urology, Central Hospital of Zao Zhuang Mineral Group, No.52 of Qilianshan Road, Xuecheng District, Zaozhuang 277800, China.

Received: 27 March 2019 Accepted: 9 September 2019

Published online: 07 October 2019

\section{References}

1. Pernar $\mathrm{CH}$. The Epidemiology of Prostate Cancer. Cold Spring Harb Perspect Med. 2018.

2. Li J. Recent trends in prostate cancer incidence by age, cancer stage, and grade, the United States, 2001-2007. Prostate Cancer. 2012.

3. Peng P, Gong YM, Bao PP, et al. Estimates and prediction of prostate cancer incidence, mortality and prevalence in China, 2008. Zhonghua Liu Xing Bing Xue Za Zhi. 2012;33:1056-9.

4. Kogan S. The clinical utility of testicular prosthesis placement in children with genital and testicular disorders. Transl Androl Urol. 2014;3:391-7.

5. Chen HX, Ning Y, Cai ZK, et al. Safety and effectiveness of testicular prosthesis implantation for testis loss: clinical observation of 18 cases. Zhonghua Nan Ke Xue. 2012;18:349-52.

6. Baird JF, Kiyak HA. The uninformed orthodontic patient and parent treatment outcomes. Am J Orthod Dentofacial Oethop. 2003:124:212-5.

7. Torre LA, Bray F, Siegel RL, et al. Global cancer statistics, 2012. CA Cancer J Clin. 2015;65:87-108.

8. Nygard R, Norum J, Due J. Goserelin (Zoladex) or orchiectomy in metastatic prostate cancer? A quality of life and cost-effectiveness analysis. Anticancer Res. 2001;21:781-8. 
9. Skoogh J, Steineck G, Cavallin-Ståhl E, et al. Feelings of loss and uneasiness or shame after removal of a testicle by orchiectomy: a population-based long-term follow-up of testicular cancer survivors. Int J Androl. 2010;33:1-10.

10. Oyama N, Mori H, Miwa Y, et al. Quality of life in patients with testicular cancer after high orchiectomy, radiation therapy or chemotherapy. Hinyokika Kiyo. 1999:45:787-92.

11. Yossepowitch O, Aviv D, Wainchwaig L, Baniel J. Testicular prostheses for testis cancer survivors: patient perspectives and predictors of long-term satisfaction. J Urol. 2011;186:2249-52.

12. Ning Y, Cai Z, Chen H, et al. Development and clinical application of a new testicular prosthesis. Asian J Androl. 2011;13:903-4.

13. Raya-Rivera AM, Baez C, Atala A, Yoo JJ. Tissue engineered testicular prostheses with prolonged testosterone release. World J Urol. 2008;26:351-8.

14. Johnson N, Cassar S, Bhatt S, Dogra VS. Fibrous capsular contracture of a testicular implant. J Ultrasound Med. 2009:28:263-5.

15. Schopf S, von Ahnen T, von Ahnen M, Schardey H. Chronic pain after laparoscopic transabdominal preperitoneal hernia repair: a randomized comparison of light and extralight titanized polypropylene mesh. World J Surg. 2011;35:302-10.

16. Reis Pdos S, Chagas VL, Silva JM, Silva PC, Jamel N, Schanaider A. Nonwoven polypropylene prosthesis in large abdominal wall defects in rats. Acta Cir Bras. 2012;27:671-80

17. Wang SM, Zhang ZY, Liu CD, Wang SZ. Study on concomitant surgical correction of pelvic organ prolapse and TVT-O for treatment of stress urinary incontinence. Zhonghua Fu Chan Ke Za Zhi. 2013;48:494-8.

18. Bodiwala D, Summerton DJ, Terry TR. Testicular prostheses: development and modern usage. Ann Royal Coll Surg Engl. 2007;89:349-53.

19. Robinson R, Tait CD, Clarke NW, Ramani VA. Is it safe to insert a testicular prosthesis at the time of radical orchidectomy for testis cancer: an audit of 904 men undergoing radical orchidectomy. BJU Int. 2016;117:249-52.

20. Yu Y, Peng L, Tang T, Chen L, Li M, Wang T. Effects of emotion regulation and general self-efficacy on posttraumatic growth in Chinese cancer survivors: assessing the mediating effect of positive affect. Psychooncology. 2014;23:473-8

\section{Publisher's Note}

Springer Nature remains neutral with regard to jurisdictional claims in published maps and institutional affiliations.

Ready to submit your research? Choose BMC and benefit from:

- fast, convenient online submission

- thorough peer review by experienced researchers in your field

- rapid publication on acceptance

- support for research data, including large and complex data types

- gold Open Access which fosters wider collaboration and increased citations

- maximum visibility for your research: over $100 \mathrm{M}$ website views per year

At $\mathrm{BMC}$, research is always in progress.

Learn more biomedcentral.com/submissions 